\title{
Seasonal variability of monoterpene emission factors for a Ponderosa pine plantation in California
}

\author{
R. Holzinger ${ }^{1, *}$, A. Lee ${ }^{1}$, M. McKay ${ }^{1}$, and A. H. Goldstein ${ }^{1}$ \\ ${ }^{1}$ University of California at Berkeley, Dept Environm Sci Policy \& Management, Berkeley, CA 94720 USA \\ * now at: Institute for Marine and Atmospheric Research Utrecht, Utrecht University, Utrecht, The Netherlands
}

Received: 11 July 2005 - Published in Atmos. Chem. Phys. Discuss.: 15 September 2005

Revised: 3 February 2006 - Accepted: 17 March 2006 - Published: 24 April 2006

\begin{abstract}
Monoterpene fluxes have been measured over an 11 month period from June 2003 to April 2004. During all seasons ambient air temperature was the environmental factor most closely related to the measured emission rates. The monoterpene flux was modeled using a basal emission rate multiplied by an exponential function of a temperature, following the typical practice for modelling temperature dependent biogenic emissions. A basal emission of $1.0 \mu \mathrm{mol} \mathrm{h}^{-1} \mathrm{~m}^{-2}$ (at $30^{\circ} \mathrm{C}$, based on leaf area) and a temperature dependence $(\beta)$ of $0.12^{\circ} \mathrm{C}^{-1}$ reproduced measured summer emissions well but underestimated spring and winter measured emissions by $60-130 \%$. The total annual monoterpene emission may be underestimated by $\sim 50 \%$ when using a model optimized to reproduce monoterpene emissions in summer. The long term dataset also reveals an indirect connection between non-stomatal ozone and monoterpene flux beyond the dependence on temperature that has been shown for both fluxes.
\end{abstract}

\section{Introduction}

Biogenic terpene emissions are very reactive and thus alter the atmosphere's oxidation capacity on local scales. In addition, terpene oxidation products like acetone and formaldehyde (Wisthaler et al., 2001; Lee et al., 2006) are potent sources of $\mathrm{HO}_{\mathrm{x}}$ radicals, and the long lifetime of acetone makes it an important $\mathrm{HO}_{\mathrm{x}}$ source in the upper troposphere. Besides the important role biogenic terpenes play in gas phase chemistry, their impact also extends to heterogeneous air chemistry. Although Went (1960) linked the formation of "blue haze" over coniferous forests to the biogenic emission of monoterpenes over 40 years ago, it wasn't until recently that terpenes received their due attention with respect to their role in secondary organic aerosol formation (SOA). O'Dowd et al. (2002) reported that nucleation events over a boreal forest were driven by condensation of terpene oxidation products. For the past few years we found increasing evidence that the total terpene emission at our Blodgett forest site is larger than typically measured over the forest canopy (Kurpius and Goldstein, 2003; Goldstein et al., 2004); other groups reported similar inferences from observations in other ecosystems (Ciccioli et al., 1999; Di Carlo et al., 2004). Recently, we observed unidentified chemical species with highest concentrations just above the canopy; these compounds are likely oxidation products of very reactive terpenoid compounds suggesting that the unaccounted terpene emissions may be 6-30 times the monoterpene emission measured at the top of the forest canopy (Holzinger et al., 2005).

Plant species that store terpenoid compounds in resin or other pools emit these compounds mainly as a function of temperature. Regional and global emission models for terpenoid compounds are typically based on this relationship and are parameterized with basal emission rates and temperature response factors obtained from field measurement campaigns in the respective ecosystems which rarely last more than a month. While other parameters like mechanical disturbance (Yatagai et al., 1995), humidity (Schade et al., 1999), and leaf expansion (Kuhn et al., 2004) are known to influence terpene emission it is not known what fraction of the total terpene emission can be attributed to additional parameters. In this paper we report above canopy measurements of monoterpene fluxes for a period of almost 11 months. We then compare our measurements to best fit models using basal emission rates and exponential temperature dependencies in order to examine how well such models perform under seasonally changing conditions.

Correspondence to: R. Holzinger

(r.holzinger@phys.uu.nl)

Published by Copernicus GmbH on behalf of the European Geosciences Union. 


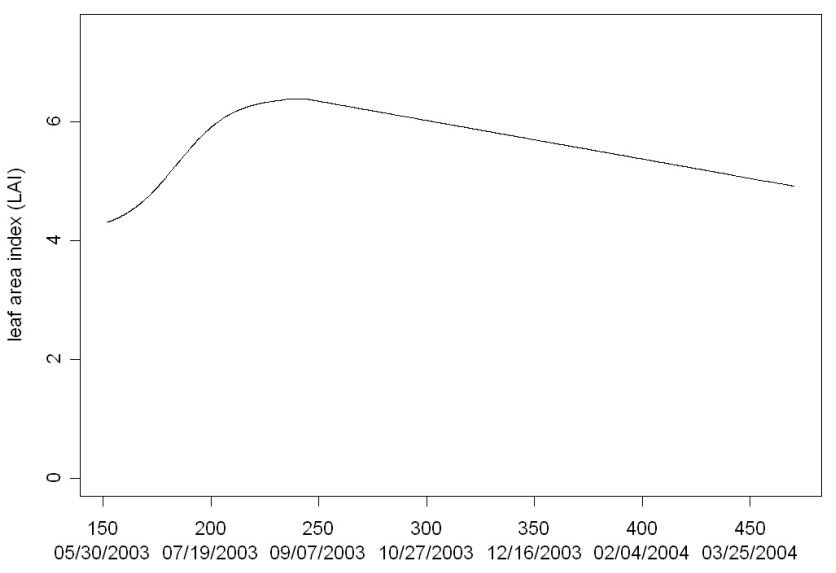

days since December 31,2002 / date

Fig. 1. Leaf area index (LAI) over the course of the study.

\section{Experimental}

The study was performed at the Blodgett forest site on the western slope of the Sierra Nevada, California $\left(38.90^{\circ} \mathrm{N}\right.$, $120.63^{\circ} \mathrm{W}$, and $1315 \mathrm{~m}$ elevation). The plantation is located $75 \mathrm{~km}$ down-wind (northeast) of Sacramento and receives anthropogenically impacted air masses rising from the valley below during the day. The site was planted with Pinus ponderosa $L$. in 1990, interspersed with a few individuals of Douglas fir, white fir, California black oak, and incense cedar. Average (median) tree height was $4.8 \mathrm{~m}$ in 2003; the canopy height was $6.4 \mathrm{~m}$, a height exceeded by $20 \%$ of the trees. The understory was composed primarily of manzanita (Arctostaphylos spp.) and whitethorn (Ceonothus cordulatus) shrubs. Local biogenic VOC emissions and the effect of transported air pollution are discussed in detail in some of our earlier work (Lamanna and Goldstein, 1999; Schade and Goldstein, 2001; Dillon et al., 2002).

The experimental setup was identical to the one which was described by Lee et al. (2005), and for detailed information on the setup and a discussion of uncertainties and errors we refer to this paper. Total monoterpenes have been measured with proton-transfer-reaction mass-spectrometry (PTR-MS) which was described by Hansel et al. (1995), a detailed review of this technique is given by Lindinger et al. (1998). The gas inlet was located next to a sonic anemometer at a height of $12.5 \mathrm{~m}$ above the ground $(\sim 4-7 \mathrm{~m}$ above the top of the trees). Through $1 / 4^{\prime \prime}$ ID Teflon PFA tubing we pulled sample air to the PTR-MS instrument which was located in an air-conditioned container next to the tower. The flow through the sample line was stabilized at a rate of 10 standard liters per minute by a flow controller (MKS instruments). One measurement cycle was completed in $0.5 \mathrm{~s}$ which included $0.2 \mathrm{~s}$ integration time on both mass 137 (protonated monoterpenes), and mass 81 (monoterpene fragment ion); the remaining $0.1 \mathrm{~s}$ were needed for acquisition of the pri- mary ion signal and the 3-dimensional wind field. Monoterpene mixing ratios were calculated from the ion signals at mass 137 and mass 81, the monoterpene fluxes were calculated according to the eddy covariance (EC) method. During the whole period gas standards (3 cylinders) were measured every $10 \mathrm{~h}$ to correct for any kind of drift and uncertainties in the reaction rate constants. We sequentially switched between 3 gas standard cylinders (Scott Marrin Inc, and Apel $\&$ Riemer) containing pure nitrogen with low mixing ratios (a few parts per million) of $\alpha$-pinene, $\beta$-pinene, and a mix of $\alpha$-pinene, $\Delta$-3-carene, and d-limonene (5:5:2), respectively. The standard and sample gas streams were mixed under turbulent conditions, so that the PTR-MS was calibrated against standard concentrations in the range of 1 $20 \mathrm{nmol} / \mathrm{mol}$. The overall error for monoterpene concentrations and fluxes should be less than $\pm 20 \%$, and $\pm 30 \%$, respectively.

At Blodgett Forest, leaves of the tree and shrub species are by far the dominant source of monoterpene emission. During summer monoterpene emission from other sources such as wood (living or dead) and leaf litter only contribute $\sim 10 \%$ or less to the total flux (Schade and Goldstein, 2003). Therefore, most of the analysis presented in this paper was done with emission rates that were normalized to leaf area rather than soil surface. These were simply calculated by dividing the measured flux (based on soil surface) by the leaf area index (LAI), the evolution of which is presented in Fig. 1. LAI is calculated using data from an inventory which is taken every year in early spring (before the growing season starts) along the footprint area. Based on these inventories the LAI for the different needle age classes is calculated from allometric equations presented in Xu et al. (2001). The evolution of LAI during the growing season is reconstructed by assuming that the dynamics of leaf area followed needle elongation, similar to Misson et al. (2005).

\section{Results}

\subsection{Seasonality of monoterpene emissions}

Figure 2a shows 30 -min average values of the physical parameters photosynthetic active radiation (PAR), air temperature, and precipitation for the 11 month (8 June 2003 to 14 April 2004) measurement period. The radiation and temperature timelines include only data taken between 10:0016:00 PST (Pacific Standard Time; equals coordinated universal time, UTC, minus $8 \mathrm{~h}$ ); thus day to night variations are not represented in the graph. In accordance with regional climatology most precipitation occurred during the winter months; however, in summer 2003 there were some rain events in July and August. The end of the summer season is marked by a sharp drop in daytime air temperatures from $26^{\circ} \mathrm{C}$ on 28 October to $0^{\circ} \mathrm{C}$ on 30 October coinciding with the first snowfall of the season. 


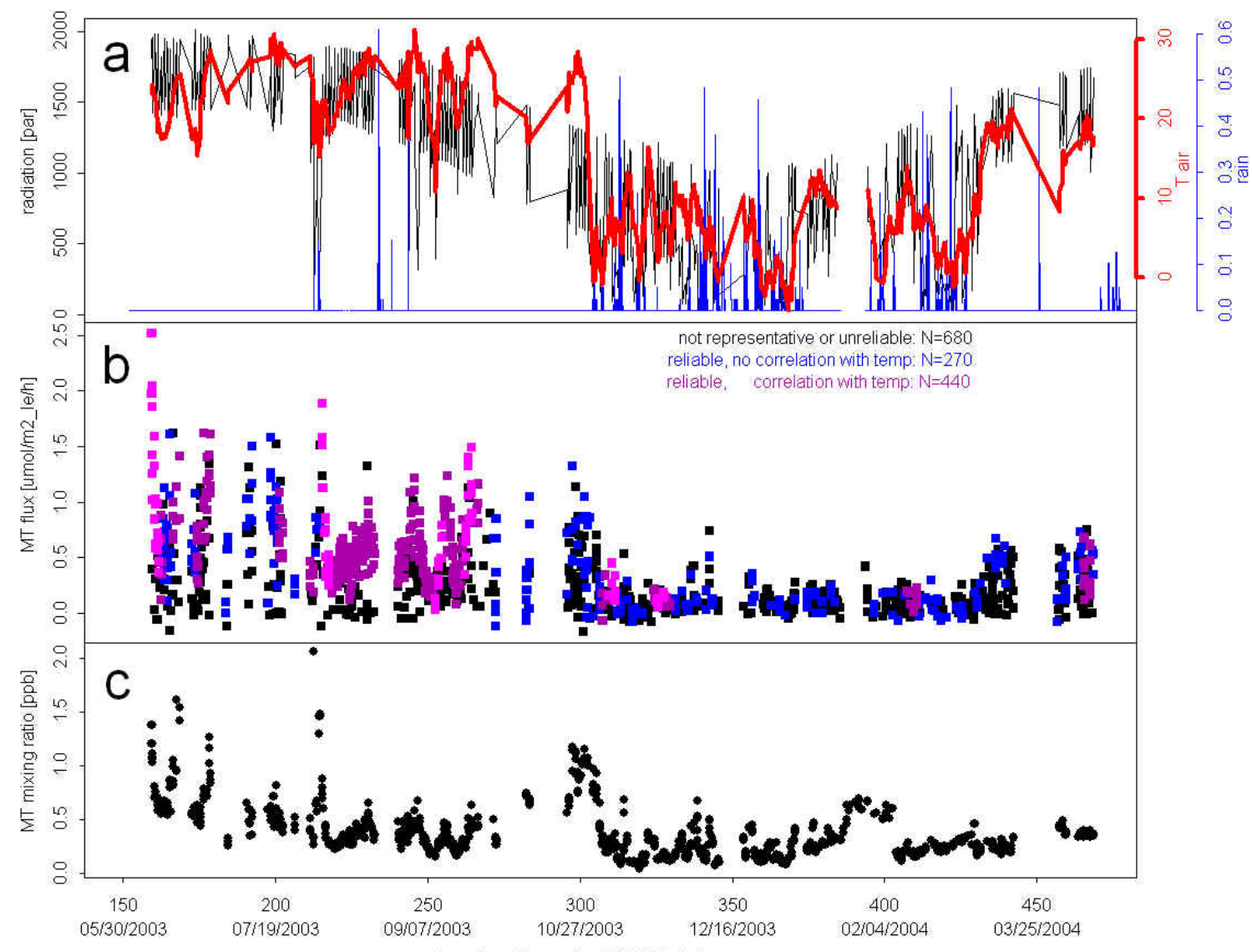

days since December 31,2002 / date

Fig. 2. 30-min average values of (a) photosynthetic active radiation (PAR), air temperature, precipitation, (b) daytime monoterpene flux, and (c) monoterpene mixing ratio in nmol/mol. Panels (a) and (c) include all data from 10:00-16:00 PST. Panel (b) color-code classification: black, unreliable data; blue, reliable data that could not be fitted short term; purple \& pink, reliable data that could be fitted short term; see text for further explanation.

Half-hour daytime (PAR $>200 \mu \mathrm{mol} \mathrm{m}^{-2} \mathrm{~s}^{-1}$ ) monoterpene flux $\left(\mathrm{MT}_{\text {flux }}\right)$ data are shown in Fig. $2 \mathrm{~b}(\mathrm{n}=1390)$. We consider the colored data-points $(n=710)$ in Fig. $2 b$ to be the most representative and reliable; they passed two general filters: (i) the wind direction came from the main footprint area of the tower $\left(130^{\circ}-290^{\circ}\right)$, and (ii) the turbulence parameter, $\mathrm{u}^{*}$, was above a conservative threshold value of $0.3 \mathrm{~m} \mathrm{~s}^{-1}$, as the eddy-covariance method becomes less reliable when turbulence is low (Goulden et al., 1996).

A scatter plot of the representative subset of data and air temperature (Fig. 3) shows that monoterpene flux exponentially increased with ambient air temperature, thus Fig. 3 suggests that even over the course of a year temperature is the main environmental parameter controlling the emission rate. However, Fig. 3 also suggests that other parameters must impact emissions since the variability of measured monoterpene fluxes at any given temperature exceeds the experimental uncertainty. The monoterpene flux was modeled (black line in Fig. 3) using the exponential relationship $\mathrm{MT}_{\text {flux }}=\mathrm{F} 30 \mathrm{e}^{(\beta(T-30))}$, were $\mathrm{F} 30$ is the basal emission rate at $30^{\circ} \mathrm{C}$, T the temperature, and $\beta$ the temperature response factor. The optimized values, obtained by non-linear least square fitting, were $1 \mu \mathrm{mol} \mathrm{m}-2$ leaf $\mathrm{h}^{-1}$ and $0.08^{\circ} \mathrm{C}^{-1}$ for $\mathrm{F} 30$ and $\beta$, respectively. Modeled and measured monoterpene fluxes are correlated but the relatively poor correlation coefficient $\left(\mathrm{r}^{2}=0.46\right)$ is another indicator of additional parameters influencing monoterpene emissions.

We were not able to improve the correlation significantly with more advanced models that, in addition to temperature, included parameters like solar radiation, humidity, leaf wetness and others; apparently monoterpene emissions are not generally triggered by any of the many other parameters that we routinely monitor at our site. To further investigate the seasonality of monoterpene emissions we analyzed the temperature dependence by looping through the data in one-day steps and forming subsets including the data of that particular day, the previous day and the following day. If the subset contained at least 6 data points, the corresponding times comprised a period of $24 \mathrm{~h}$ or more, and the corresponding temperatures comprised a range of $2.5^{\circ} \mathrm{C}$ or more, 


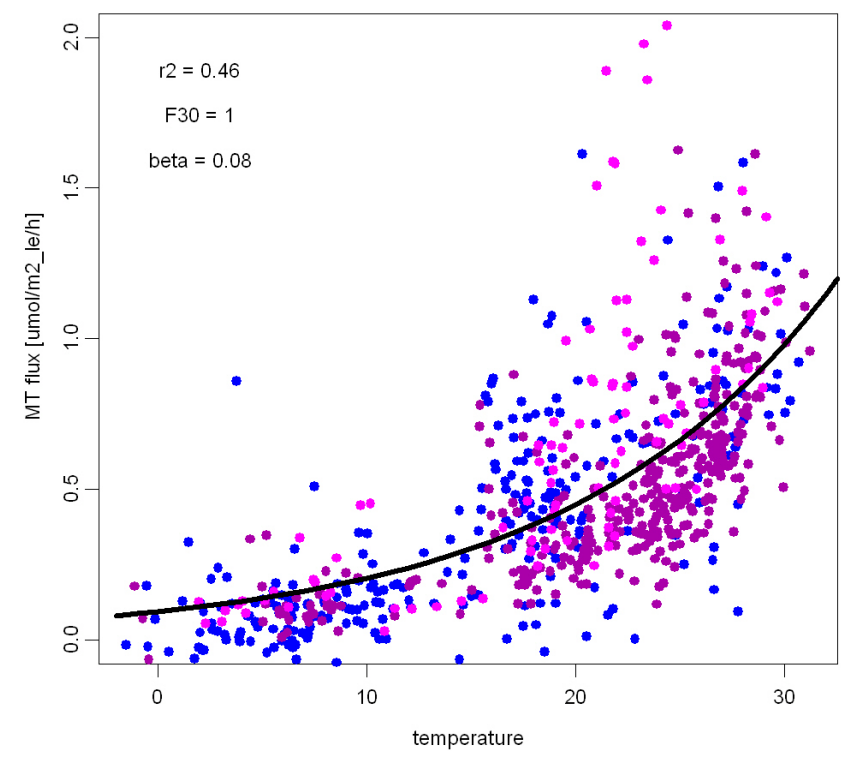

Fig. 3. Scatter plot of ambient air temperature and monoterpene flux including all reliable daytime data under representative wind conditions. The rather poor correlation between modeled and measured monoterpene fluxes $\left(r^{2}=0.46\right)$ indicates other emission controls in addition to temperature. The color code is the same as in Fig. $2 b$.

we modeled the subset by means of non linear fitting. Data points that could be modeled and were reasonably correlated with observations $\left(\mathrm{r}^{2}<0.25\right)$ were separated and the $\mathrm{F} 30_{i}$ and $\beta_{i}$ parameters were compiled. In Fig. $2 \mathrm{~b}$ these 440 data points are plotted in purple, whereas the 270 data points plotted in blue squares could not be reasonably modeled.

Example scatter plots of modeled and measured $\mathrm{MT}_{\text {flux }}$ over short time periods are shown in Figs. 4a-f; data points included in Fig. 4 are plotted in light purple squares in Fig. 2b. Subsets c and d represent typical summer and subset $f$ represents typical winter conditions. Non linear fitting of these subsets yielded basal emission rates (F30) and temperature response factors $(\beta)$ similar to those obtained from fitting the entire dataset. Both the F30 and the $\beta$ parameter were significantly higher in models for subsets $a, b$, and e. Measurements from Subset a date from 8-10 June and represent typical springtime measurements; high monoterpene emission was observed on days following rain events late in July and early August (subset b) and after the first snowfall on 31 October (subset e).

A more general picture is obtained from Fig. 5 which is a scatter plot of measured and modeled $\mathrm{MT}_{\text {flux }}$ of all subsets versus ambient air temperature. Measurements that could be modeled according to the procedure described above are printed as grey solid squares; those that could not be modeled are displayed as grey open circles. All model results representing typical summer or winter conditions are positioned along an "exponential band" and are displayed as black solid circles in Fig. 5. Model results outside the "band of nor- mal" could either be attributed to precipitation events or they represent times early in the growing season. Precipitation events that marked the end of a longer period without rain or snowfall were followed by bursts of monoterpene emissions, but the emission capacity of the ecosystem was not permanently enhanced when rain or snowfall occurred: no significant emission burst followed the rain event of $31 \mathrm{Au}-$ gust which was preceded by several other rain events (see Fig. 2); similarly, no significant bursts followed the many snow or rainfalls in November after the first one on 31 October. In addition to the enhanced emission following precipitation events a seasonal cycle is apparent in Fig. 5: monoterpene fluxes in spring 2003 were much larger than in any other season, and in early spring 2004 this cycle began to start over again.

The insights gained from fitting short time periods allow to improve the model performance over longer periods: we formed another subset of data including all typical summer and winter data, and excluding precipitation events and spring data. Values of $1 \mu \mathrm{mol} \mathrm{m}-2 \mathrm{leaf}^{-1}$ and $0.12^{\circ} \mathrm{C}^{-1}$ for model parameters $\mathrm{F} 30$ and $\beta$, respectively, were obtained from fitting this subset. Since we excluded all non-typical and unreliable data points we consider these values to be the most accurate and representative overall model parameter for our site, which is also expressed by the high correlation $\left(\mathrm{r}^{2}=0.74\right)$ between measured and modeled $\mathrm{MT}_{\text {flux }}$. The modeled $\mathrm{MT}_{\text {flux }}$ is represented by the solid green line in Fig. 5. Comparing the overall model with the results from the short time period modeling (Fig. 5) reveals an additional seasonality - more subtle than the enhanced emission during spring: in accordance with measurements, most model results adapted to short time periods in winter predict about 50 $100 \%$ larger monoterpene emissions than the overall model at the given temperature range. In contrast, during summer the short time period modeling results appear symmetrically scattered around the results of the overall model (green line in Fig. 5).

In the following we will evaluate the overall model with respect to the actual measurements over the course of the year in order to quantitatively assess the seasonality. It is useful to define following time periods: "all": 8 June 2003 to 14 April 2004, "spring 2003": before 28 June 2003, "summer": 28 June to 29 October 2003, "winter": 30 October 2003 to 28 February 2004, "spring 2004": after 28 February 2004, "rain event", 2-6 August 2003, and "first snow event": 30 October to 7 November 2003. The mean modeled and measured monoterpene flux for these periods is presented in Table 1. The measured exceeded the modeled $\mathrm{MT}_{\text {flux }}$ in each of the defined periods. The best agreement was obtained for the summer data. On average measured values were $9 \%$ above the modeled ones; the disagreement decreased to $5 \%$ when data during the rain event were excluded. Modeled and measured summer-means are in excellent agreement (better than $\pm 0.5 \%$ ) when data not reasonably correlated with temperature were excluded (not shown). During winter and spring 

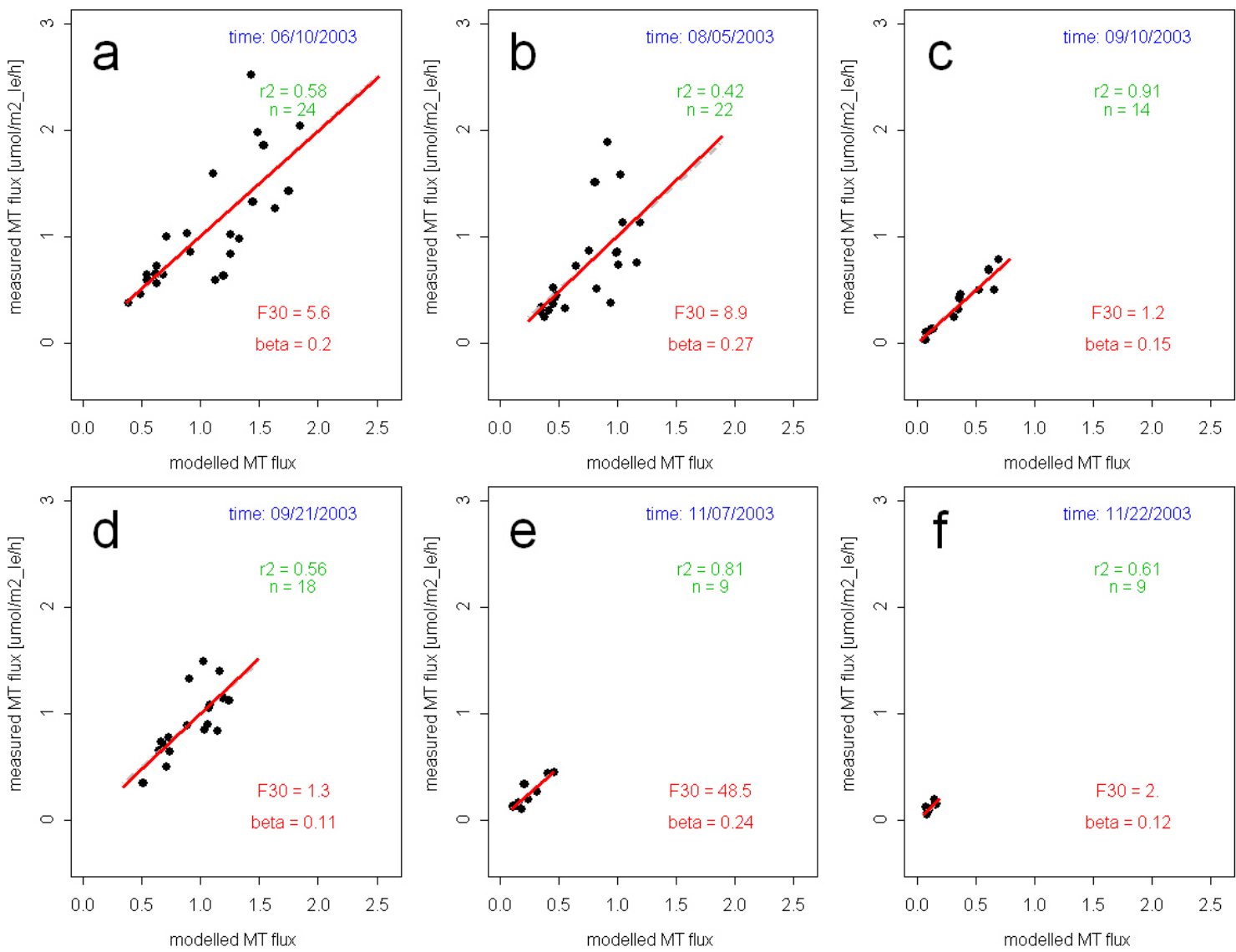

Fig. 4. Example results of models optimized to reproduce measurements of short time periods of 2-3 days. While most model parameters were within the expected range (panels $\mathbf{c}, \mathbf{d}$, and f), others were significantly enhanced (panels $\mathbf{a}, \mathbf{b}$, and e). The higher monoterpene emissions were observed after precipitation events and in spring.

Table 1. Mean monoterpene flux (modeled and measured) in $\mu \mathrm{mol} \mathrm{m}_{\text {leaf }}^{-2} \mathrm{~h}^{-1}$. All reliable and representative data (blue \& purple in Fig. 2b).

\begin{tabular}{lrrrrrrrrr}
\hline & all & $\begin{array}{r}\text { spring } \\
2003\end{array}$ & $\begin{array}{r}\text { spring } \\
2004\end{array}$ & summer & $\begin{array}{r}\text { Summer excluding } \\
\text { rain event }\end{array}$ & $\begin{array}{r}\text { rain } \\
\text { event }\end{array}$ & $\begin{array}{r}\text { winter } \\
\text { winter excluding first snow } \\
\text { event }\end{array}$ \\
\hline Modeled 1 & 0.37 & 0.36 & 0.21 & 0.51 & 0.53 & 0.29 & 0.06 & 0.05 \\
measured & 0.48 & 0.83 & 0.39 & 0.56 & 0.55 & 0.64 & 0.11 & 0.06 \\
\# number of data & 710 & 97 & 44 & 403 & 375 & 28 & 166 & 0.10 & 0.21 \\
\%-difference & 31 & 134 & 89 & 9 & 5 & 121 & 87 & 144 \\
\hline
\end{tabular}

${ }^{1} \mathrm{~F} 30=1.0 \mu \mathrm{molh}^{-1} \mathrm{~m}^{-2}, \beta=0.12{ }^{\circ} \mathrm{C}^{-1}$

the actual monoterpene emissions were $60-130 \%$ higher than the model had predicted; the enhancement due to the rain events are also encompassed by this range, and the $\sim 300 \%$ enhancement following the first snow fall is striking but has to be interpreted in the context of very low modeled emissions. With all data put together, the mean-measured flux was $30 \%$ higher than the mean-modeled flux. Considering that spring and winter data are underrepresented in our dataset (see Table 1), the difference between modeled and real mean- annual monoterpene emission likely is larger than this number. The annual mean $\mathrm{MT}_{\text {flux }}$ can be calculated according to

$$
\begin{aligned}
F_{\text {annual }}= & \left(0.5 \times F_{\text {spring } 2003}+0.5 \times F_{\text {spring2004 }}\right. \\
& \left.+F_{\text {summer }}+F_{\text {winter }}\right) / 3
\end{aligned}
$$

when the year is equally divided into spring, summer and winter season. Equation (1) yields values of 0.43 and $0.29 \mu \mathrm{mol} \mathrm{m}_{\text {leaf }}^{-2} \mathrm{~h}^{-1}$ for real and modeled mean-annual 
Table 2. Correlation between non-stomatal ozone flux and monoterpene emission.

\begin{tabular}{ccccc}
\hline $\begin{array}{c}\text { temperature bin } \\
{\left[{ }^{\circ} \mathrm{C}\right]}\end{array}$ & $\begin{array}{c}\text { number of } \\
\text { datapoints }\end{array}$ & $\begin{array}{c}\text { monoterpene flux } \\
{\left[\mu \mathrm{mol} \mathrm{m}^{-2} \mathrm{~h}^{-1}\right]}\end{array}$ & $\begin{array}{c}\text { non-stomatal ozone flux } \\
{\left[\mu \mathrm{mol} \mathrm{m}^{-2} \mathrm{~h}^{-1}\right]}\end{array}$ & $\begin{array}{c}\text { correlation } \\
\text { (pearson's r) }\end{array}$ \\
\hline $15-16.9$ & 23 & 2.28 & -22.3 & -0.37 \\
$16.9-18.8$ & 58 & 2.3 & -28.0 & -0.2 \\
$18.9-20.8$ & 63 & 2.49 & -24.3 & -0.31 \\
$20.8-22.7$ & 53 & 3.38 & -32.7 & -0.6 \\
$22.7-24.6$ & 81 & 3.47 & -30.8 & -0.39 \\
$24.6-26.5$ & 76 & 3.69 & -30.6 & -0.49 \\
\hline
\end{tabular}

${ }^{1}$ within a bin monoterpene fluxes were not correlated with temperature $\left(\mathrm{r}^{2}<0.02\right)$.

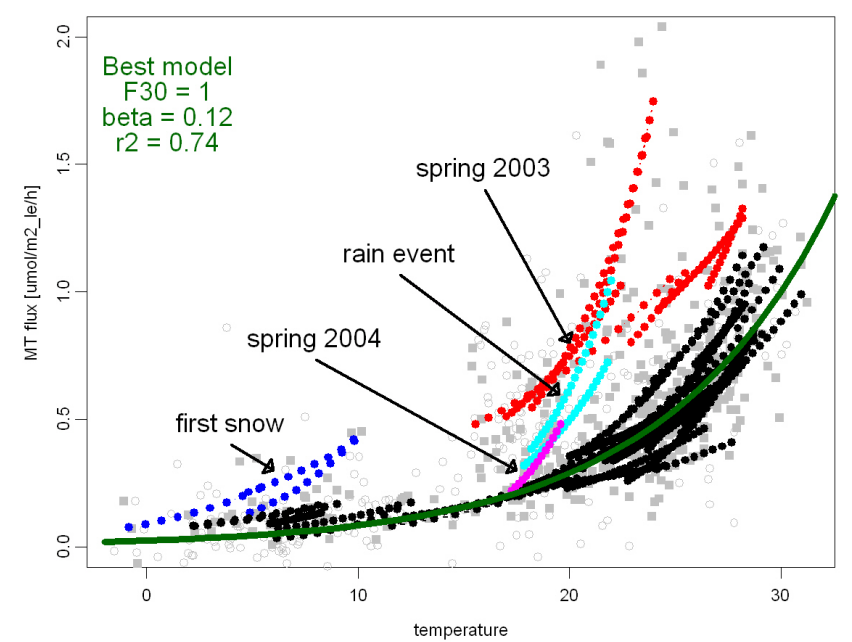

Fig. 5. Measured monoterpene flux (grey symbols) and model results. All results from short time period modeling are included. The best overall model for our site (represented by the green line) is well correlated with measurements $\left(r^{2}=0.74\right)$.

monoterpene emissions, respectively, so our data suggest that the best model for the Blodgett site underestimates the real emissions by $\sim 50 \%$ over the course of a year.

The figure of $50 \%$ was derived from comparison of numbers that have an estimated error up to $30 \%$ (see experimental section), however, seasonally averaged fluxes (Table 1) have been calculated from a large number of single measurements, and therefore statistical noise is minimized. Similarly, if systematic errors or other accuracy problems are an issue, they should impact average values of all seasons in the same way, thus minimizing any systematic errors when comparing different seasons. We consider scaling with the leaf area index to be the largest uncertainty because we do not know if monoterpene emissions from leaves are as dominant in spring and winter as they are in summer. If the data are analysed without scaling to leaf area the model still underestimates measured emissions by more than $30 \%$. However, it is very likely that during spring and winter a very significant fraction of monoterpene is emitted from leaves and needles and we consider the figure of $50 \%$ more realistic.

\subsection{Monoterpene and non-stomatal ozone flux}

We also used the long term dataset to test if there was a correlation between monoterpene emission and non-stomatal ozone flux into the canopy. In earlier work we hypothesized that during summer a large fraction of the ozone flux into the canopy was due to chemical reaction of ozone with very reactive terpenoid compounds that were emitted through similar mechanisms as the monoterpenes but at larger quantities (Kurpius and Goldstein, 2003; Holzinger et al., 2005). Table 2 shows that monoterpene flux and non-stomatal ozone flux (both based on ground area) are correlated beyond their shared dependence on ambient air temperature which has been demonstrated in earlier work. Monoterpene fluxes in a temperature range of $\sim 2^{\circ} \mathrm{C}$ are no longer correlated with ambient air temperature, however, a significant correlation between non-stomatal ozone flux and monoterpene emission still exists within these small temperature ranges. Correlation coefficients $\left(\mathrm{r}^{2}\right)$ of $0.04-0.36$ seem to be low but we also have to consider that ozone and monoterpene fluxes have been measured with completely different instrumentation all with their specific sources of random error; besides, the nonstomatal ozone flux is not directly measured but calculated from the total ozone flux and the canopy conductance according to Kurpius and Goldstein (2003). The direct correlation between $\mathrm{O}_{3 \text {,flux-ns }}$ and $\mathrm{MT}_{\text {flux }}$ strongly suggests that along with the emission of monoterpenes large amounts of other substances are released that react with ozone and cause the observed chemical $\mathrm{O}_{3 \text {,flux-ns }}$. Thus data presented in Table 2 supports the hypothesis that the oxidation products reported by Holzinger et al. (2005) are at least in part products from such ozone-terpenoid reactions.

\section{Conclusions and implications}

Most regional and global air chemistry models calculate monoterpene emission using the same relation we used for 
our analysis $\left(\mathrm{MT}_{\mathrm{flux}}=\mathrm{F} 30 \mathrm{e}^{(\beta(T-30))}\right)$; parameters $\mathrm{F} 30$ and $\beta$ are defined for different ecosystems and usually no additional seasonality is taken into account. The parameterization of the models is based on availability of experimental data; as for monoterpene emission the F30 and $\beta$ values for many ecosystems come from field experiments that were performed during summer. Our 11 month field study shows, however, that the actual emissions in spring and winter are $60-130 \%$ higher than this approach would yield. Over the course of a year, the total monoterpene emission could be underestimated by $50 \%$. Besides ambient air temperature actual monoterpene emissions are influenced by additional parameters that play important roles. Advanced biosphere-atmosphere exchange models include additional parameters and reproduce the seasonal cycle better than our simple model. Such parameters include seasonal variation of the leaf area index, short term temperature history (daysweeks), and leaf age (Guenther et al., 2000). However, detailed knowledge on these parameters is only available for a few types of biogenic emission; e.g. the isoprene emission from young and old leaves is lower than from middle-aged leaves. If this were also true for monoterpene emissions at the Blodgett forest site, we should have observed lower basal emissions in spring and winter when the average leaf age is youngest and oldest, respectively. However, the opposite is the case and our observations are in accordance with Kuhn et al. (2004) who also observed opposite response of monoterpene and isoprene emission with respect to leaf age. Plants may produce individual monoterpene species for different purposes and therefore they may exhibit different seasonal cycles. Lerdau et al. (1994) found that the emission pattern of $\Delta$-3-carene was strikingly different from other monoterpenes observed in their study; as for our study it may well be that the monoterpene composition is quite different in summer and winter, which has been observed by Staudt et al. (2000) for a Mediterranean pine species (Pinus pinea). Differently to Staudt et al. (2000), however, at the Blodgett Forest site the basal monoterpene emission was higher in spring and winter and lower in summer. We conclude that mechanisms leading to monoterpene emission have to be understood better in order to improve the parameterization of biogenic emission and thus atmospheric chemistry models.

Acknowledgements. This research was funded by the National Science Foundation Atmospheric Chemistry Program (awards ATM-0119510 and 0443448), the California Air Resources Board (ARB contract number 00-732), and the University of California Agricultural Experiment Station. We thank B. Heald, D. Rambeau, and the Blodgett Forest crew for operational support, and Sierra Pacific Industries for use of their land and assistance in field site operations.

Edited by: A. B. Guenther

\section{References}

Ciccioli, P., Brancaleoni, E., Frattoni, M., Di Palo, V., Valentini, R., Tirone, G., Seufert, G., Bertin, N., Hansen, U., Csiky, O., Lenz, R., and Sharma, M.: Emission of reactive terpene compounds from orange orchards and their removal by within-canopy processes, J. Geophys. Res., 104(D7), 8077-8094, 1999.

Di Carlo, P., Brune, W. H., Martinez, M., Harder, H., Lesher, R., Ren, X. R., Thornberry, T., Carroll, M. A., Young, V., Shepson, P. B., Riemer, D., Apel, E., and Campbell, C.: Missing OH reactivity in a forest: Evidence for unknown reactive biogenic VOCs, Science, 304(5671), 722-725, 2004.

Dillon, M. B., Lamanna, M. S., Schade, G. W., Goldstein, A. H., and Cohen, R. C.: Chemical evolution of the Sacramento urban plume: Transport and oxidation, J. Geophys. Res. 107(D5-6), doi:10.1029/2001JD000969, 2002.

Goldstein, A. H., McKay, M., Kurpius, M. R., Schade, G. W., Lee, A., Holzinger, R., and Rasmussen, R.: Forest thinning experiment confirms ozone deposition to forest canopy is dominated by reaction with biogenic VOCs, Geophys. Res. Lett., 31(L22106), doi:10.1029/2004GL021259, 2004.

Goulden, M. L., Munger, J. W., Fan, S. M., Daube, B. C., and Wofsy, S. C.: Measurements of carbon sequestration by longterm eddy covariance: Methods and a critical evaluation of accuracy, Global Change Biology, 2(3), 169-182, 1996.

Guenther, A. B., Zimmerman, P. R., Harley, P. C., Monson, R. K., and Fall, R.: Isoprene and Monoterpene Emission Rate Variability - Model Evaluations and Sensitivity Analyses, J. Geophys. Res., 98(D7), 12 609-12 617, 1993.

Guenther, A., Geron, C., Pierce, T., Lamb, B., Harley, P., and Fall, R.: Natural emissions of non-methane volatile organic compounds; carbon monoxide, and oxides of nitrogen from North America, Atmos. Environ., 34, 2205-2230, 2000.

Hansel, A., Jordan, A., Holzinger, R., Prazeller, P., Vogel, W., and Lindinger, W.: Proton-Transfer Reaction Mass-Spectrometry Online Trace Gas-Analysis at the Ppb Level, A., Int. J. Mass Spectrom., 150, 609-619, 1995.

Holzinger, R., Lee, A., Paw, U. K. T., and Goldstein, A. H.: Observations of oxidation products above a forest imply biogenic emissions of very reactive compounds, Atmos. Chem. Phys., 5, 67-75, 2005

Kuhn, U., Rottenberger, S., Biesenthal, T., Wolf, A., Schebeske, G., Ciccioli, P., Brancaleoni, E., Frattoni, M., Tavares, T. M., and Kesselmeier, J.: Seasonal differences in isoprene and lightdependent monoterpene emission by Amazonian tree species, Global Change Biology, 10(5), 663-682, 2004.

Kurpius, M. R. and Goldstein, A. H.: Gas-phase chemistry dominates O-3 loss to a forest, implying a source of aerosols and hydroxyl radicals to the atmosphere, Geophys. Res. Lett., 30(7), doi:10.1029/2002GL016785, 2003.

Lamanna, M. S. and Goldstein, A. H.: In situ measurements of C-2-C-10 volatile organic compounds above a Sierra Nevada ponderosa pine plantation, J. Geophys. Res., 104(D17), 21247 $21262,1999$.

Lee, A., Goldstein, A. H., Keywood, M. D., Gao, S., Varutbangkul, V., Bahreini, R., Flagan, R. C., and Seinfeld, J. H.: Gasphase products and secondary aerosol yields from the ozonolysis of ten different terpenes, J. Geophys. Res., 111, D07302, doi:10.1029/2005JD006437, 2006. 
Lee, A., Schade, G. W., Holzinger, R., and Goldstein, A. H.: A comparison of new measurements of total monoterpene flux with improved measurements of speciated monoterpene flux, Atmos. Chem. Phys., 5, 505-513, 2005.

Lerdau, M. T., Dilts, S., Lamb, B., Allwine, E., and Westberg, H.: Monoterpene emissions from Ponderosa pine, J. Geophys. Res., 99(D), 16609-16615, 1994.

Lindinger, W., Hansel, A., and Jordan, A.: On-line monitoring of volatile organic compounds at pptv levels by means of protontransfer-reaction mass spectrometry (PTR-MS) - Medical applications, food control and environmental research, Int. J. Mass Spectrom., 173(3), 191-241, 1998.

Misson, L., Tang, J., Xu, M., McKay, M., and Goldstein, A. H.: Influences of recovery from clear-cut, climate variability, and thinning on the carbon balance of a young ponderosa pine plantation, Agric. Forest Meteorol., 130(3-4), 207-222, 2005.

O’Dowd, C. D., Aalto, P., Hameri, K., Kulmala, M., and Hoffmann, T.: Aerosol formation - Atmospheric particles from organic vapours, Nature, 416(6880), 497-498, 2002.

Schade, G. W. and Goldstein, A. H.: Fluxes of oxygenated volatile organic compounds from a ponderosa pine plantation, J. Geophys. Res., 106(D3), 3111-3123, 2001.

Schade, G. W., Goldstein, A. H., and Lamanna, M. S.: Are monoterpene emissions influenced by humidity?, Geophys. Res. Lett., 26(14), 2187-2190, 1999.
Schade, G. W. and Goldstein, A. H.: Increase of monoterpene emission from a pine plantation as a result of mechanical disturbances, Geophys. Res. Lett., 30(7), 1380, doi:10.1029/2002GL016138, 2003.

Staudt, M., Bertin, N., Frenzel, B., and Seufert, G.: Seasonal variation in amount and composition of monoterpenes emitted by young Pinus pinea trees - Implications for emission modelling, J. Atmos. Chem., 35, 77-99, 2000.

Tingey, D. T., Manning, M., Grothaus, L. C., and Burns, W. F.: Influence of Light and Temperature on Monoterpene Emission Rates from Slash Pine, Plant Physiology, 65(5), 797-801, 1980.

Went, F. W.: Blue Hazes in the Atmosphere, Nature, 187(4738), 641-643, 1960.

Wisthaler, A., Jensen, N. R., Winterhalter, R., Lindinger, W., and Hjorth, J.: Measurements of acetone and other gas phase product yields from the $\mathrm{OH}$-initiated oxidation of terpenes by protontransfer-reaction mass spectrometry (PTR-MS), Atmos. Environ., 35(35), 6181-6191, 2001.

Xu, M., DeBiase, T. A., Qi, Y., Goldstein, A. H., and Liu, Z. G.: Ecosystem respiration in a young ponderosa pine plantation in the Sierra Nevada Mountains, California, Tree Physiology, 21(5), 309-318, 2001.

Yatagai, M., Ohira, M., Ohira, T., and Nagai, S.: SeasonalVariations of Terpene Emission from Trees and Influence of Temperature, Light and Contact Stimulation on Terpene Emission, Chemosphere, 30(6), 1137-1149, 1995. 